\title{
De adoratorios prehispánicos a capillas familiares otomíes
}

From pre-Hispanic shrines to Otomi family chapels

Ana Laura Medina Manrique

Doctorado en Historia y Estudios Humanísticos, Universidad Pablo de Olavide, Sevilla (almedman@alu.upo.es)

Recibido el 31 de mayo de 2017; revisado el 16 de junio de 2017; aceptado el 17 de julio de 2017; publicado el 01 de septiembre de 2017

RESUMEN: Las capillas y oratorios domésticos han sido lugares importantes en el culto religioso de algunas comunidades indígenas de México. Este breve recorrido histórico iniciará con los antiguos templos prehispánicos, finalizando con el tratamiento de las capillas familiares otomíes de los siglos XVIII-XIX, en la localidad de San Miguel Tolimán. Se explicará el origen e importancia de estas capillas dentro de la tradición del culto en espacios sagrados, que ha influido en la identidad de los otomíes del centro de México.

PALABRAS CLAVE: Historia, evangelización, oratorio doméstico, espacios de culto, San Miguel Tolimán.

\begin{abstract}
The chapels and domestic oratories have been the important places in the religious worship of some mexican indigenous communities. This brief historical tour will begin with the ancient precolonial temples, finishing with the treatment of the otomi chapels of the XVIII-XIX centuries, in the locality of San Miguel Tolimán. I will explain the origin and importance of these chapels in the tradition of sacred spaces that has influenced in the identity of the Otomies of central Mexico.
\end{abstract}

KEYWORDS: history, evangelism, domestic oratory, worship spaces, San Miguel Tolimán. 
Desde sus orígenes, la religiosidad ha estado vinculada no sólo a la imagen del dios y su intervención en el mundo, sino a los lugares de culto a los que los creyentes han acudido como resultado de la sacralización de un espacio relacionado con la presencia divina. Los oratorios domésticos han permitido la comunicación del hombre con lo divino a través de ofrendas y rituales que buscan asegurar el vínculo entre lo cotidiano y lo trascendental.

\section{Espacios de culto antes y durante la conquista}

Históricamente, la resistencia de los indígenas en adoptar la nueva religión se vio reflejada en el apego a sus adoratorios y rituales practicados ante la amenaza de la destrucción de sus creencias. En este panorama, los evangelizadores reutilizaron los espacios sagrados en los que impusieron imágenes cristianas que los naturales asociaron con sus deidades. Una cédula real del año 1538 describe esta situación de la siguiente manera (Real Cédula al Virrey de la Nueva España, 1538, núm. 1088, 1. 3, f. 167):

"Hay informes de que los naturales usan todavía sus vitos gentílicos y de noche van a sus adoratorios, cues y templos; que haga derrocar y quitar todos los cues y templos de ídolos y adoratorios de ellos con aquella prudencia que convenga de manera que de derribarlos no resulta escándalo entre los naturales y de la piedra de ellos se torne para hacer iglesias y monasterios [...] y procuren que se busquen los ídolos y que se quemen".

Con este tipo de iniciativas, los misioneros aprovecharon la tradición ceremonial del hombre prehispánico, practicada en sus lugares sagrados, para lograr que una efectiva asimilación del cristianismo echara raíces en la religiosidad indígena. La destrucción de sus templos y la edificación de iglesias cristianas propició con el tiempo una reinterpretación cosmogónica revelada en las crónicas del siglo XVI. Fray Bernardino de Sahagún menciona varias veces la presencia de oratorios domésticos y de barrio, dedicados al culto de las deidades indígenas (Sahagún, 1938, p. 44 y 114).

"En este capulli donde se contaba este mercader ponían el báculo en lugar venerable [...] todas las veces que comía este mercader ofrecía primeramente y las demás cosas al báculo, que le tenía en su oratorio, dentro de su casa. [...] Tenían edificados oratorios a honra de estos dioses en todos los barrios donde había dos calles; los cuales llamaban Cihuateocalli, o por otro nombre Cihuateupan”. 
La presencia de oratorios domésticos antes de la conquista afianzó la costumbre de significar la vivienda familiar como centro sagrado del cual emergían vínculos de parentesco ligados a la creencia en una figura divina. Así mismo, la referencia de Sahagún también muestra la necesidad de crear templos en los diferentes barrios de una población, con la finalidad de reforzar los vínculos sociales a nivel colectivo.

Por otro lado, la relación "espacio-ritual” se expone en la cita de Fray Gerónimo de Mendieta en su Historia Eclesiástica Indiana (Mendieta, 1870, p. 101 y 104):

"Que en todos los lugares que dedicaban para oratorios, tenían sus ídolos grandes y pequeños: y los tales lugares $[\ldots]$ eran sin número, en los templos principales y no principales de los pueblos y barrios, y en sus patios. [...] Eran los cantos y bailes, así para solemnizar las fiestas de sus demonios que por dioses honraban [...] y por esta causa [...] en cada pueblo y cada señor en su casa tenía capilla con sus cantores, componedores de danzas y cantares".

Esta conjunción simbólica se daba a través de danzas y música dedicadas a los diferentes dioses de una sociedad tradicionalmente politeísta. De igual manera, el hecho de identificar diversos tipos de templos señala que dentro de la religiosidad prehispánica existía una jerarquía del espacio vinculada a la división del ritual público y privado.

Ya en el siglo XVII, las licencias para la construcción y celebración de ceremonias religiosas en capillas particulares de México evidenciaron la importancia de estos espacios domésticos en la vida ritual de la población novohispana. Un documento del año 1600 nos sitúa en Querétaro, lugar donde se realiza la siguiente petición (Diversas peticiones y licencias, 1600: caja 653, exp. 1, f. 1v.):

“Anton de Arango vecino del pueblo de Querétaro digo que yo tengo [...] mucha gente de servicio del y entre ellos algunos indios chichimecos esclavos y por ser en tierra de guerra en donde hay mucho riesgo que podría suceder salir chichimecos a quitarlos de que resultaría muchos daños y alborotarse la tierra $[\ldots]$ pido y suplico sea servido de dar licencia [...] para que los domingos y fiestas de guardar un sacerdote pueda decir misa a la gente del servicio [...] tengo capilla decente y los ornamentos y demás cosas que fuesen necesarias".

La anterior solicitud muestra el vínculo entre las capillas y el culto cristiano que, con tintes evangélicos, buscaba la pacificación de los indígenas chichimecas. Así mismo, estas concesiones de licencia se enfocaban en "oratorios para las casas de su habitación, y de campo, altares portátiles, y capillas rurales 
[...] y oratorios" (Para que en estos reinos se observe la ley, 1787, vol. 136, exp. 166, f. 286v). Es importante mencionar que una distribución y tipología de oratorios similares siguen vigentes en la actualidad. La clasificación de capillas domésticas y altares portátiles nos conducen a San Miguel Tolimán, sitio en el que se encuentran varios ejemplos de oratorios con una gran importancia a nivel religioso y social.

\section{Las capillas familiares otomíes}

El padrón general de fincas rústicas y urbanas de San Miguel Tolimán, realizado en 1855 (Inventario, vol. 1, 2009, p. 86-87), indica que en el barrio centro se identificaron tres capillas: Los Reyes, Los Pérez y Los Elías. En el barrio de la Cruz del Milagro se identificaron siete capillas correspondientes a las familias de Santiago, Carvajal, Junquillal y Pérez. En el barrio Peña Blanca se ubicaron siete capillas más, propiedad de las familias Jiménez, Morales, Elías, Pintor, Rico y López. De un total de 17 capillas contadas, dos fueron clasificadas como comunitarias mientras que el resto se identificaron como familiares.

Debido al número de oratorios, algunos de estos no se ven reflejados en el padrón de 1855. Sin embargo, es probable que las primeras capillas se construyeran a partir de los trabajos de edificación de la iglesia principal en 1750, fecha que se corrobora en una petición del año 1789 (Licencia para que se celebra el santo sacrificio de la misa, 1789: caja 575, exp. 104, f. 1r-4v).

"El cura juez de San Pedro Tolimán [...] dice que [...] diez y ocho años que sirve este curato donde se halló con la iglesia real pueblo de San Miguel de esta doctrina en sus primeros principios y comenzaron el año de mil setecientos y cincuenta los naturales de San Miguel a costa de su trabajo, siguiendo a sus sudores los naturales para pagar a los maestros y de suerte que ellos lo han costeado todo [...] lo han hecho cincuenta y un personas las haya ayudado: yo cura, no les he dicho nada para ello; sólo si el animarlos al fin de la conclusión de esta obra, lo que incesantemente ha hecho debiéndole a sus repetidas insistencias ver acabado esto a costa de gran trabajo con el que ha construido".

En esta solicitud también se menciona la función de capilla pública que la iglesia de San Miguel tendría en la comunidad, hecho que indica el posible inicio de la tradición de los oratorios familiares otomíes.

Los otomíes aún conservan sus creencias asociadas al mundo prehispánico y a los actores que participaron en una nueva construcción simbólica de los espacios rituales. En San Miguel Tolimán, las 
capillas fueron construidas como lugares sacros que representan al primer miembro bautizado de un linaje a quien se le denomina $x_{i t a}{ }^{1}$, considerándolo una especie de divinidad (Chemín, 1993, p. 75). La influencia cristiana también se observa en ritos de paso como el bautismo y el culto a los antepasados. Este último se expresa en la veneración de los abuelitos mecos o chichimecas ${ }^{2}$ y la devoción a los familiares difuntos realizada a través de ceremonias y objetos rituales como las cruces de ánimas (Chemín, 1993, p. 75).

Las capillas familiares otomíes [1] fueron concebidas en un contexto evangelizador que pretendía la transmisión de la religión cristiana a los grupos indígenas del semidesierto queretano, en el centro de México. Sin embargo, las reminiscencias prehispánicas quedaron en la cosmovisión local materializándose en estos oratorios, cuyos orígenes están relacionados con antiguos templos y las ceremonias que en ellos se realizaban.

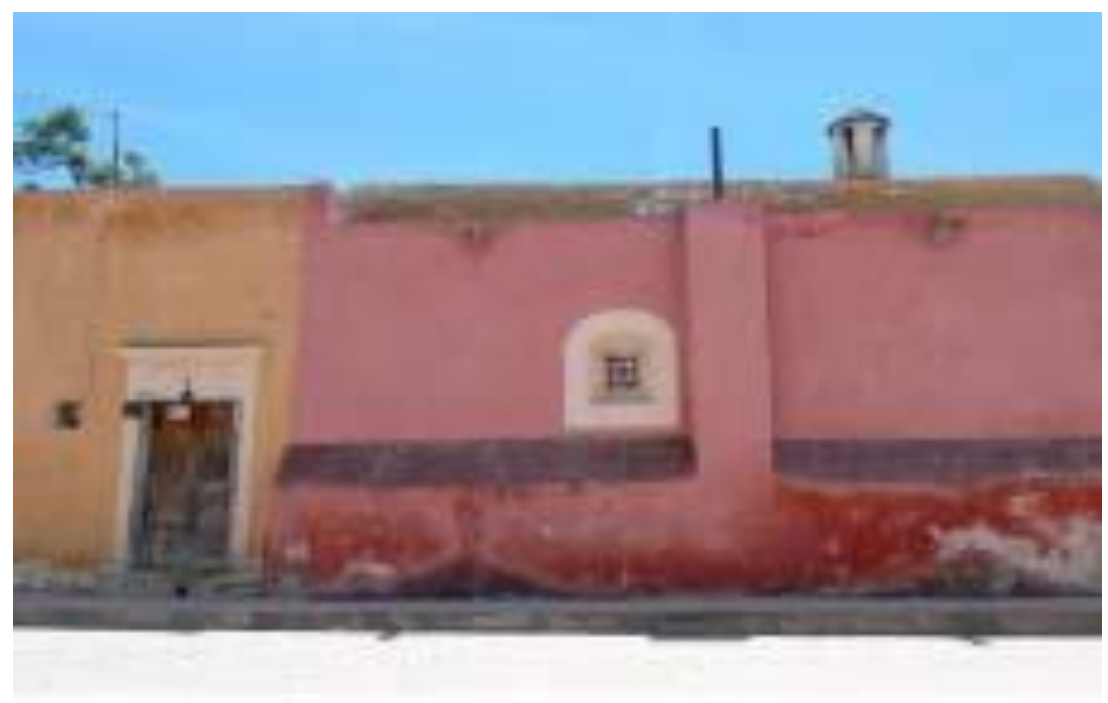

[Fig. 1] Capilla otomí. Fotografía de Ana Laura Medina (2016), San Miguel Tolimán.

Hay veintidós (Chemín, 1993, p. 78) descendencias dueñas de las capillas. Entre ellas existe una jerarquía basada en la antigüedad, el origen de su antepasado y su situación económica; por lo que no es de extrañar que las capillas más importantes sean propiedad de las familias más antiguas. La mayor parte de las capillas fueron nombradas con el apellido del fundador del linaje, este hecho se puede observar en los oratorios que llevan los apellidos Reséndiz, Santiago, Luna [2], Pérez, etcétera.

\footnotetext{
${ }^{1}$ Del otomí, xita se traduce al español como "hombre viejo (Hekking et alt., 1989, p. 192).

${ }^{2}$ Los chichimecas fueron una tribu seminómada que habito un territorio fronterizo entre Aridoamérica y Mesoamérica, ocupando los actuales estados de Querétaro y Guanajuato (Prieto et alt., 2012, p. 51).
} 
Otras capillas tienen un nombre relacionado con el lugar en el que fueron construidas o la profesión del antepasado fundador (Chemín, 1993, p. 85-85).

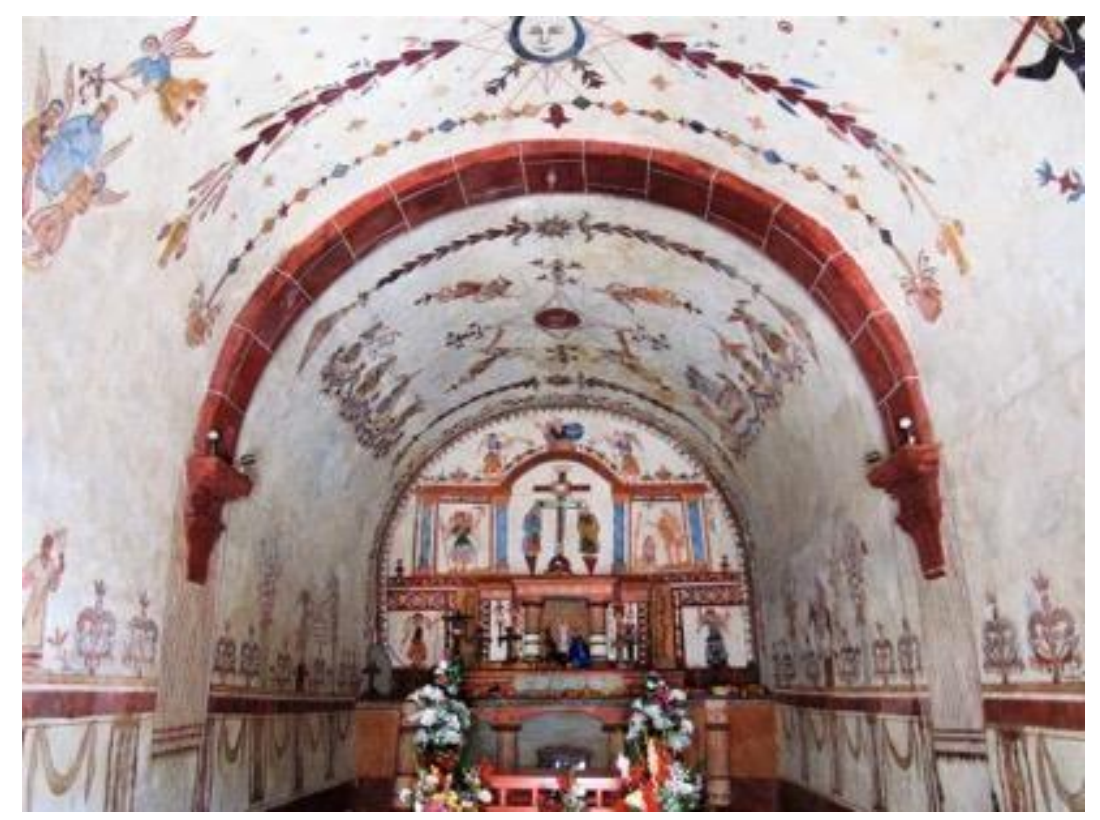

[Fig. 2] Capilla de la familia Luna. Fotografía de Ana Laura Medina (2016), San Miguel Tolimán.

$\mathrm{Su}$ composición las clasifica en cinco tipologías compuesta de diversos elementos arquitectónicos (Lugares de Memoria, (Lugares de Memoria, 2010, p. 91):

a) Capilla, atrio, calvario principal y calvario fuera del atrio [3].

b) Capilla y calvario principal.

c) Capilla aislada.

d) Conjunto de calvarios.

e) Calvario aislado.

La simplicidad de su traza arquitectónica se resume en una planta rectangular de una sola nave. Dividido en dos entre ejes, el oratorio puede tener una bóveda de arista o de cañón. De acuerdo a su organización espacial, pueden ser de acceso frontal o lateral formando un solo eje longitudinal entre el calvario, la entrada y la mesa de ofrendas. También pueden poseer dos ejes perpendiculares formados a partir de la composición de la capilla, la entrada y el calvario (Inventario, vol. 1, 2009, p. 97). 


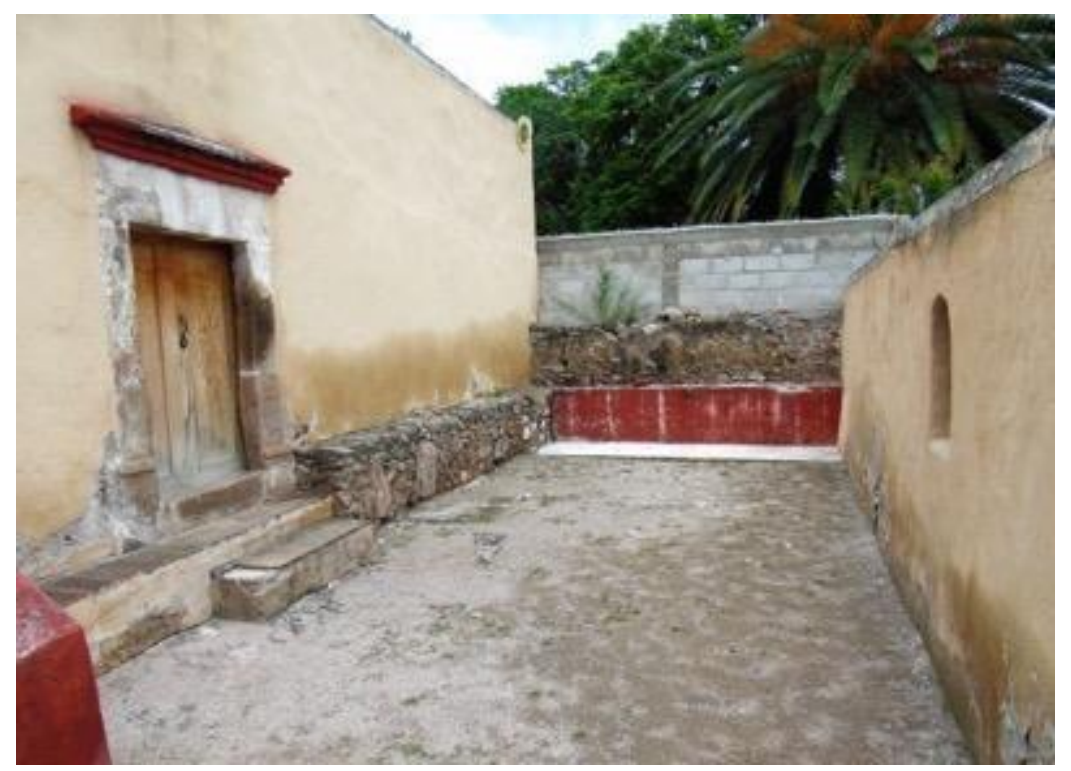

[Fig. 3] Tipología “a”, capilla San Diego. Fotografía de Ana Laura Medina (2016), San Miguel Tolimán.

Los calvarios (Lugares de Memoria, 2010, p. 93-94) son espacios pequeños en donde se depositan cruces de madera u ofrendas mortuorias. Por su ubicación, se catalogan en calvarios principales, ubicados de manera lineal al acceso principal; y calvarios secundarios, situados dentro del predio con dimensiones y orientación distintas. Su posición frente a la entrada del oratorio, simboliza el medio de comunicación directa entre los dos espacios sagrados.

\section{Conclusiones}

Diversas son las manifestaciones religiosas que a través de los años han dado identidad a los pueblos indígenas de México. En el mosaico simbólico de la devoción cristiana, permanecen elementos de origen prehispánico que mantienen el pasado vivo en espacios como los oratorios domésticos. La presencia de un mundo sagrado dentro de la cotidianeidad del entorno familiar ha permitido que el curso habitual de los acontecimientos se mezcle con la ritualidad y el mundo de lo sagrado a través de ceremonias que los otomíes de San Miguel han reproducido durante mucho tiempo. El conocer el origen y evolución de sus lugares de culto permitirá ampliar nuestra visión sobre la práctica ritual en México, así como su importancia cultural, histórica y social.

La importancia de las capillas descansa en todos los elementos que las integran y muestran su función como espacios de culto. Su historia, resultado del mestizaje cultural y artístico, revela los 
cimientos de dos culturas materializadas en una arquitectura europea hecha con materiales locales; una religión occidental que se impuso a la cosmovisión de los pueblos originarios; y una nueva identidad producto de su historia y presente.

\section{Referencias bibliográficas}

CASTILlO, Aurora (2000), Persistencia histórico-cultural: San Miguel de Tolimán, Universidad Autónoma de Querétaro: Querétaro.

CHEMÍN, Heidi (1993), Las capillas oratorios otomíes de San Miguel Tolimán. Ya t’ulo nijõ dega södi ñuhu ya mengu Nxemge, Fondo Editorial de Querétaro, Consejo Nacional para la Cultura y las Artes, Dirección General de Culturas Populares Unidad Regional-Querétaro: Querétaro.

DIVERSAS PETICIONES Y LICENCIAS (1600), Diversas peticiones y licencias para celebrar servicios religiosos en capillas y oratorios particulares México, Archivo General de la Nación, México, grupo documental Bienes Nacionales, caja 653, exp. 1, f. 1v.

HEKKING, Ewald; ANDRÉS DE JESÚS, Severiano (1989), Diccionario español-otomí de Santiago de Mexquititlán, Universidad Autónoma de Querétaro: Querétaro.

INVENTARIO (2009), Inventario de las Capillas familiares otomí-chichimeca, vol. 1, Poder Ejecutivo del Estado de Querétaro: Querétaro.

LICENCIA PARA QUE SE CELEBRE EL SANTO SACRIFICIO DE LA MISA (1789), Licencia para que se celebre el santo sacrificio de la misa en la iglesia de San Miguel del partido de San Pedro Tolimán, Archivo General de la Nación, México, grupo documental Bienes Nacionales,México caja 575, exp. 104, f. 1r-4v.

LUGARES DE MEMORIA (2010), Lugares de Memoria y Tradiciones vivas de los pueblos OtomíChichimeca de Tolimán. La Peña de Bernal, guardián de un territorio sagrado, Poder Ejecutivo del Estado de Querétaro: Querétaro. 
MENDIETA, Jerónimo de (1870), Historia eclesiástica indiana, Antigua Librería, Portal de Agustino no. 3: México.

NOMBRAMIENTO DE LOS RELIGIOSOS (1652), Nombramiento de los religiosos de la orden de San Francisco, Archivo General de la Nación, México, unidad documental Reales Cédulas Originales y Duplicados, vol. 17, exp. 88, f. 98v- 100r.

\section{NOMBRAMIENTO DEL PADRE FR. ANTONIO DE ACEVEDO (1671), Nombramiento del} padre Fr. Antonio de Acevedo de la orden de San Francisco, Archivo General de la Nación, México, unidad documental Reales Cédulas Originales Y Duplicados, vol. 29, exp. 175, f. 312r-315r.

PARA QUE EN ESTOS REINOS SE OBSERVE LA LEY (1787), Para que en estos reinos se observe la ley que se inserta sobre la impetración y concesión de licencia de oratorios domésticos así urbanos como rurales, Archivo General de la Nación, México, grupo documental Reales Cédulas Originales, vol. 136, exp. 166, f. 286v.

PRIETO, Diego; UTRILLA, Beatriz (2012), “Amalgama de culturas: La región chichimeca otomí del semidesierto de Querétaro y Guanajuato", en VALLE, Julieta; PRIETO, Diego; UTRILLA, Beatriz (coord.), Los pueblos indígenas de la Huasteca y el semidesierto queretano, atlas etnográfico, pp. 51-67, Instituto Nacional de Antropología e Historia (INAH), Instituto Nacional de Lenguas Indígenas (INALI), Universidad Autónoma de Querétaro (UAQ), Instituto Queretano de la Cultura y las Artes (IQCA) : Querétaro.

REAL CÉDULA AL VIRREY DE LA NUEVA ESPAÑA (1538), Real Cédula al Virrey de la Nueva España, Archivo General de Indias, Sevilla, grupo documental Registro de Oficios y Partes, Audiencia de México, núm. 1088, L. 3, f. 167r.

RESÉNDIZ, Francisco (1997), Municipio de Tolimán, Gobierno del Estado de Querétaro: Querétaro.

SAHAGÚN, Bernardino de (1938), Historia general de las cosas de la Nueva España, vol. 1, editorial Pedro Robredo: México. 
SOLICITUD DEL FRAILE BARTHOLOME (1603), Solicitud del fraile Bartholome de la Concepción, Archivo General de la Nación. México, unidad documental Indiferente Virreinal, caja 3379, exp. 3, f. 1r. 